\title{
RISKY SEXUAL AND HEALTH BEHAVIOURS AND IMPACT ON PSYCHO-SOCIAL DEVELOPMENT OF ADOLESCENTS IN TERTIARY INSTITUTIONS IN ENUGU STATE, NIGERIA
}

\author{
Okeke, Nkechi Uzochukwu' ${ }^{1 i}$, \\ Anierobi, Elizabeth Ifeoma ${ }^{2}$, \\ Oparaugo, Ursula Ifeoma ${ }^{2}$
}

${ }^{1} \mathrm{PhD}$, Department of Educational Foundations, Nnamdi Azikiwe University, Awka, Anambra State, Nigeria ${ }^{2}$ Department of Educational Foundations, Nnamdi Azikiwe University, Awka, Anambra State, Nigeria

\begin{abstract}
:
Adolescents due to the experimentation and exploration drive that characterize the period often engage in risky sexual and health behaviours being ignorant of the consequences on their health and psychological well-being. The study adopted ex-postfacto research design to find out risky sexual and health behaviours and impact on psycho-social development of adolescents in tertiary institutions in Enugu state. Four research questions guided the study. A total of 300 students in 300 and 400 levels in three selected higher institutions in Enugu state formed the sample of the study. Data were collected through questionnaire of 40 items to elicit information on the impact of risky sexual and health behaviours on psycho-social development of adolescents. The instrument was validated by experts in education. Reliability of the instrument was determined using Cronbach Alpha and an alpha coefficient of 0.78 was obtained. Research questions were answered using frequencies, percentages and mean. Result revealed the prevalence of risky sexual and health behaviours among adolescents in tertiary institutions in Enugu state. It also revealed that risky sexual and health behaviours are associated with frustration, low self-esteem, feelings of guilt, sense of regret, abandonment by parents/siblings and loss of self-respect among others. The researchers recommend family interventions (good parental training and monitoring), counseling and rehabilitation services, emotional regulation skills and self-management skills training.
\end{abstract}

i Correspondence: email drnkechiokeke@gmail.com, un.okeke@unizik.edu.ng 
Keywords: risky sexual, health behaviours, adolescents, tertiary institutions, psychosocial development

\section{Introduction}

Sex from creation of man is ordained by God for procreation. Therefore, sex is normal and healthy part of life. However, there are two sides of the coin as far as sex is concerned namely: sex can either be a need or a want. A need is something that is necessary for an organism to live a stable and healthy life which includes shelter, land, food, water, sex and air. On the other hand, a want is a wish, desire or aspiration. Supporting the above, Maslow (1970) a renowned psychologist in his hierarchy of human needs included sex, air, food, water and rest as physiological needs/survival needs. This is simply because they are experienced throughout the life span on a daily basis. On a need basis, sex is vital for procreation, and this preserves the society from going into extinction but at the same time caution, due selection and agreement of the persons involved is vital. Often it is sex on the basis of want that leads to risky sexual and health behaviours because it is done indiscriminately, without due selection and choice, forcefully just to satisfy few seconds urge.

Put in another form, an individual can absolutely survive without sex for his/her entire life but if a society lived celibate, we would quickly go into extinction since sex is necessary for procreation. Marriage was the first institution ordained by God for procreation and is achievable through sexual intercourse between a man and a woman. Despite the fact that sex is necessary for procreation, premarital sex remains an unacceptable norm/ taboo socially, culturally and religiously.

In Igbo traditional society in Anambra state of Nigeria where the researchers came from, sex is not a subject for open discussions. Premarital sex is a taboo and has many grave psychological and social consequences but unfortunately some adolescents in their experimental drive and exploration escapades engages in risky sexual and health behaviours such as homosexual, lesbian, masturbation, pornography, drug, rape and alcohol use among others. A close observation of modern time adolescents in tertiary institutions reveals that most of them are sexually active and they place a high value on love making (sexual intercourse) as a prerequisite for relationships damning the consequences. While in the lecture hall, they are dating through various social media handles, while walking on the street they are kissing and hugging each other without respect for any adult around the scene. This is quite very unfortunate and contrary to societal standard which demands that due respect and prestige be accorded to relationship. Of course yes, for this is what makes man different from lower animals like $\mathrm{dog}$, cat and hen among others. Adolescents' sexual behaviour poses a great concern to educationists, psychologists and researchers because of the social consequences which range from unwanted pregnancy, abortion, hawking of babies, contacting of sexually transmitted diseases, suicidal attempt to drop-out from school. 
Doubova, Martinez-Vega, Infante-Castaneda and Perez-Cuevas (2017) assert that early pregnancy and unsafe sex pose a threat worldwide to adolescents' health and wellbeing. The World Health Organization (2012) noted that adolescence is no longer children and neither adult. WHO emphasized that adolescence are: - Period of rapid physical and psychological (cognitive and emotional) growth.

1) Period of development of new capacities, and

2) Period of changing social relationships, expectations, roles and responsibilities.

Allen and Waterman (2019) assert that adolescence is the period of transition between childhood and adulthood which is accompanied by biological and social changes. Adolescence is seen as a time to develop independence from parents while still remaining connected to them for provision of educational and material needs. Allen and waterman opined that the typical age range of adolescence is from 12 to 18 years and this stage has remarkable physical, cognitive and psycho-social characteristics. Okeke and Joe-Akunne (2020) noted that most of the university students are in their late adolescence period and early adulthood period- a period when they are filled with life and energy. At that period, they are yet to develop proper self-identity and many draw their identity from peer group perceived "tough guys" criterion, as they seem to be doing presently and often more exert their physical energy in social vices including risky sexual and health behaviours. For example, in higher institutions of learning, adolescents of opposite sex live in the same room (though unmarried and also their parents being ignorant of their activities) all through their 4-6 years course/programme duration in the university experimenting with all manner of contraceptives, pills, drugs and even family planning methods.

Some adolescents engage in risky sexual and health behaviours that affect their psychological well being. World Health Organization (2002) defined sexual health as:

a. A state of physical, emotional, mental and social well-being related to sexuality, it is not merely the absence of disease, dysfunction or infirmity,

b. Sexual heath requires a positive and respectful approach to sexuality and sexual relationships, and

c. Sexual health involves the possibility of having pleasurable and safe sexual experiences devoid of coercion, discrimination and violence.

On the other hand, unhealthy sexual behaviour can lead to deviance from any of the above-mentioned points.

Olaleye, Obiyan and Folayan (2020) noted that sexual risk behaviour included irregular use of condom, having multiple sex partners (indiscriminate sex life) and sex for money (transactional sex). Getachew, Genet, Meseret, Worku, Mikiyas, Tiguaded, Meless and Melat (2016) explained risk sexual behaviour as behaviours related to sexuality which exposes an individual to contacting sexually transmitted diseases such as HIV and AIDs. Supporting the above, researchers including Nishtha and Siddharth (2019) and Keto, Tilahun and Mamo (2020) assert that risky sexual behaviour explains the activity that will heighten the chance that a person engaging in sexual activity with a carrier of any form of sexually transmitted disease will also be infected OR become 
pregnant. Nishtha et al noted that risky sexual behaviour can mean two similar things namely: The behaviour itself and the description of the partner's behaviour.

Risky sexual and health behaviours in the context of this research work refers to indulgence in indiscriminate sex life style which increases the probability of an individual contacting sexually transmitted diseases that poses serious health challenge as well as affecting the psycho-social development of a person. Adolescents' engagement in risk sexual and health behaviours in tertiary institutions in Nigeria is worrisome. It is observed that while technology has changed the way in which adolescents interact and access information, they remain a vulnerable population when it comes to risky sexual behaviours. Adolescents are also especially vulnerable to sexual risk because they are undergoing rapid cognitive, behavioural, emotional and social development. Most parents probably because of societal norms/values has failed to give adequate and proper sex education to their children as and when due, hence these adolescents resort to their peers, internets, digital technology for their desired knowledge. Thus, they end up getting both negative and positive information from these sources which either builds or destroy their future.

Tertiary institutions in the context of this research mean the education level following the completion of secondary education. Tertiary education includes universities, colleges of education, colleges of agriculture and polytechnics. Tertiary education generally culminates in the receipt of certificates, diplomas, academic degrees as well as honorary awards. UNESCO (2011) noted that tertiary education includes academic, as well as vocational or professional education. It is built on secondary education, providing learning activities in specialized field of education aimed at high level of complexity and specialization.

Some researchers including Getachew et al (2016), Keto et al (2020) observed that adolescents are the most vulnerable group of risky sexual and health behaviours. The reason may be traced to the many physical, sexual, cognitive, social and emotional changes that took place during this stage of life which can bring anticipation and anxiety for the young adult. A large number of adolescents are involved in risky sexual and health behaviours such as early sexual initiation, commercial sex hawking, non-usage of condom and indiscriminate sex.

Family, parental, economic, religious and social factors are associated with adolescents' risky sexual and health behaviours. Most parents probably because of illiteracy (poor educational background), very tight business and career schedules, religious doctrine, limited exposure, societal beliefs have failed in their role of child's training and upbringing and as such the child is left at the mercy of their peers and social media (Facebook, Twitter, WhatsApp among others) for their desired knowledge and thus end up getting both negative and positive information which either builds or destroys their destiny. Srahbzu and Tirfeneh (2020) noted socio-economic status, joblessness, sexually active friends, family instability, single-parent household, sibling sexual activity to be among the causes of adolescents' involvement in risky sexual behaviours. Abdissa, Addisie and Seifu (2017) opined that contributing factors to risky 
sexual behaviours include poor socio-economic status, environment, harmful traditional practices, low contraceptive use and voluntary counseling and testing utilization. Olusegun (2019) observed that one of the factors contributing to involvement in sexual activities is peer pressure that is, adolescents' desire to belong with their peers. Adolescents who perceive their peers to be sexually active will likely engage in same to remain acceptable. In addition, Shrestha (2019) opined that multidimensional factors which include parental relationship, cultural and traditional rules and values, school environment, social media lead to risky sexual behaviours.

Some adolescents engage in risky sexual behaviours that affect their psycho-social development. In the context of this research work, psycho-social development implies behavioural and social functioning of an individual that is, the development of a person's cognitive, emotional, intellectual and social capabilities and functioning over the course of a normal life span. Social development refers to how people develop social and emotional skills across the lifespan. Healthy social development allows us to form positive relationships with family, friends, teachers and other people in our lives. Social development can be affected by child's personality, the opportunities they have for social interaction, behaviours learned from parents as well as developmental disorders.

Adolescents often are ignorant of dangers of involvement in risky sexual and health behaviours, the right protective measures as well as right channels of information regarding any health challenge. The researchers believe that intervention in risky sexual and health behaviours of adolescents are vital to prevent chronic health conditions bearing in mind that these young people are the future leaders of tomorrow and therefore the need to preserve this generation is vital. Quite a number of researches had been done on the contributing factors to risky sexual behaviour but none to the best of knowledge of the researchers has addressed the issue of impact of risky sexual and health behaviours on psycho-social development of adolescents. It is against this background that the researchers want to investigate risky sexual and health behaviours and impact on psychosocial development of adolescents in tertiary institutions in Enugu state with the view to proffering psychological and social measures that will be effective in reducing the social menace.

\section{Statement of Problem}

Adolescents' involvement in sexual activities in tertiary institutions in Nigeria poses great concern to any right-thinking individual. Most adolescents are more sexually active than their parents due to exposure to social media. Adolescents often do not perceive sex to be risky because of wrong thoughts and information they have about sexuality both from their peers and social media. They are impulsive and tend to fantasize, so they do not consider the consequences of their actions. Adolescent stage marks a period of independence in life when young people try to live outside their parents attention and also see their parents advice, instruction and corrections as "out-dated", "obsolete" and "out-of-place". No wonder you often hear young people from Igbo traditional society in 
Nigeria address their parents with slogans such as "Okoh-man", Okoh-woman", "My old man" and "My old woman".

In the university, following pressures from peer group, attempt to belong to a particular class or group of persons, information from social media, university environment becomes a place for a variety of activities and opportunities for socialization including sex activities. Young adults sought for love and to be loved thus engaging in premarital sex. The researchers intend to investigate risky sexual and health behaviours and impact on psycho-social development of adolescents.

The study is guided by four research questions which include:

1) What is the prevalence of risky sexual and health behaviours among adolescents in higher institutions in Enugu state?

2) What are the contributing factors to adolescents' engagement in risky sexual and health behaviours?

3) What are the impacts of risky sexual and health behaviours on the adolescents' psycho-social development?

4) What psychological and social measures could be effective in reducing adolescents' indulgence in risky sexual and health behaviours?

\section{Method}

Ex-post-facto research design was used for the study. This type of research design seeks to establish cause-effect relationships. The researcher usually has no control over the variables of interest and therefore cannot manipulate them. Indeed, the researcher only attempts to link some already existing effects or observations to some variable(s) as causative agent(s) (Nworgu, 2015). The study was carried out in Enugu state using three government owned institutions (state government and federal government). These three institutions namely University of Nigeria, Nsukka, Enugu state University of Science and Technology and Institute of Management and Technology, Enugu state were selected using purposive random sampling technique. From the chosen institutions, simple random sampling was employed to select 50 students each in 300 and 400 levels of study respectively from the Faculty of Engineering, Environmental sciences and Management Sciences. Therefore, the sample size comprised of 300 students.

A researcher-developed instrument titled "Impact of Risky Sexual and Health Behaviours on Psycho-social Development of Adolescents" (IRSHBPDA) was used for data collection. The instrument has four sections with a total of 40 items. It was structured on a 4-point likert scale ranging from strongly agree, agree, disagree to strongly disagree. Three experts in the Department of Educational Psychology and Measurement and Evaluation from Nnamdi Azikiwe University, Awka validated the instrument. The reliability of the instrument was determined using Cronbach alpha with an overall reliability coefficient of 0.78 .

The researchers, with the aid of three trained research assistants, administered the questionnaire directly to the chosen sample for the study. A total of 300 copies of the 
questionnaire were given out and all were successfully completed and returned. The research questions were answered using frequencies, percentages and mean. Acceptance point for the items was 2.50 and any mean below 2.50 was regarded as rejected.

\section{Result}

Table 1: Adolescents response on the prevalence of risky sexual and health behaviours in tertiary institutions in Enugu state $(\mathrm{N}=300)$

\begin{tabular}{|l|c|c|}
\hline \multicolumn{1}{|c|}{ Prevalence } & Students Frequency & Percentage (\%) \\
\hline Sometimes & 39 & 13 \\
\hline Always & 65 & 21.7 \\
\hline Rarely & 47 & 15.7 \\
\hline Never & 32 & 10.7 \\
\hline Often & 117 & 39 \\
\hline
\end{tabular}

Table 1 reveals the following percentages as depicting the extent of students' indulgence in risky sexual and health behaviours in higher institutions in Enugu state: Sometimes$13 \%$, always $-21.7 \%$, rarely $-15.7 \%$, never $-10.7 \%$ and often $-39 \%$.

Table 2: Mean and standard deviation scores of students on the contributing factors to students indulgence in risky sexual behaviours $(\mathrm{N}=300)$

\begin{tabular}{|c|l|c|c|c|c|c|c|}
\hline S/N & Items & SA & A & D & SD & X & Remark \\
\hline 1 & Lustful desires & 94 & 76 & 70 & 60 & 2.68 & Agree \\
\hline 2 & Greed & 88 & 87 & 65 & 60 & 2.67 & Agree \\
\hline 3 & Moral bankruptcy & 81 & 69 & 76 & 74 & 2.52 & Agree \\
\hline 4 & Uncontrollable desire for material things & 85 & 82 & 77 & 56 & 2.65 & Agree \\
\hline 5 & Poor parental training and upbringing & 73 & 111 & 60 & 56 & 2.67 & Agree \\
\hline 6 & Influence of social media & 63 & 126 & 72 & 39 & 2.71 & Agree \\
\hline 7 & Peer influence & 43 & 197 & 41 & 19 & 2.88 & Agree \\
\hline 8 & Being possessed of evil spirit or demons & 57 & 103 & 99 & 41 & 2.59 & Agree \\
\hline 9 & Indecent/provocative dressing & 83 & 145 & 70 & 3 & 3.02 & Agree \\
\hline 10 & Influence of drug/alcohol & 90 & 85 & 65 & 60 & 2.68 & Agree \\
\hline
\end{tabular}

Table 2 shows that the students with a mean score of 2.50 and above agreed that the 10 items in the instrument which include lustful desires, uncontrollable desire for material things, moral bankruptcy, poor parental training and upbringing, influence of social media, indecent/provocative dressing among others were some of the contributing factors to students' indulgence in risky sexual and health behaviours.

Table 3 shows that the students with a mean score of 2.50 and above agreed that all the 10 items in the instrument which include frustration, negative self-concept, low self-esteem/inferiority complex, health problems, sense of guilt, feeling of regret, despair, loss of friendship, loss of self-respect, abandonment by parents, withdrawn behaviour were among the impact of risky sexual and health behavour on the psycho-social development of adolescents. 
Table 3: Mean and standard deviation scores of students on impact of risky sexual and health behaviours on the psycho-social development of adolescents $(\mathrm{N}=300)$

\begin{tabular}{|c|l|c|c|c|c|c|c|}
\hline S/N & Items & SA & A & D & SD & $\mathbf{X}$ & Remark \\
\hline 11 & Withdrawn behaviour & 78 & 76 & 76 & 70 & 2.54 & Agree \\
\hline 12 & Loss of friendship & 98 & 72 & 72 & 58 & 2.70 & Agree \\
\hline 13 & Loss of self respect/prestige & 98 & 82 & 62 & 58 & 2.73 & Agree \\
\hline 14 & Abandonment by parents/siblings & 85 & 86 & 74 & 55 & 2.67 & Agree \\
\hline 15 & Shame and reproach to family & 39 & 133 & 68 & 60 & 2.50 & Agree \\
\hline 16 & Thwarts academic pursuit & 100 & 185 & 10 & 5 & 3.27 & Agree \\
\hline 17 & School dropout & 202 & 97 & 1 & - & 3.67 & Agree \\
\hline 18 & Suicidal attempt & 61 & 159 & 61 & 19 & 2.87 & Agree \\
\hline 19 & Feeling of unhappiness/sad & 27 & 167 & 51 & 55 & 2.55 & Agree \\
\hline 20 & Stigmatization & 46 & 146 & 60 & 48 & 2.63 & Agree \\
\hline 21 & Frustration & 80 & 140 & 23 & 57 & 2.81 & Agree \\
\hline 22 & Negative self concept & 140 & 120 & 21 & 19 & 3.27 & Agree \\
\hline 23 & Low self esteem/inferiority complex & 70 & 95 & 75 & 60 & 2.58 & Agree \\
\hline 24 & Health problems & 92 & 88 & 65 & 55 & 2.72 & Agree \\
\hline 25 & Sense of guilt & 78 & 97 & 65 & 60 & 2.64 & Agree \\
\hline 26 & Feeling of regret & 58 & 112 & 65 & 62 & 2.55 & Agree \\
\hline 27 & Despair & 88 & 107 & 55 & 50 & 2.78 & Agree \\
\hline 28 & Depression & 93 & 87 & 53 & 67 & 2.69 & Agree \\
\hline 29 & Humiliation & 220 & 64 & 6 & 10 & 3.65 & Agree \\
\hline 30 & Aggressive behaviours & 46 & 131 & 80 & 43 & 2.60 & Agree \\
\hline
\end{tabular}

Table 4: Mean and standard deviation scores of students on psycho-social measures that could be effective in reducing risky sexual and health behaviours among adolescents $(\mathrm{N}=300)$

\begin{tabular}{|c|l|c|c|c|c|c|c|}
\hline S/N & Items & SA & A & D & SD & X & Remark \\
\hline 31 & $\begin{array}{l}\text { Family interventions: Good parental training and proper } \\
\text { monitoring }\end{array}$ & 30 & 155 & 64 & 51 & 2.55 & Agree \\
\hline 32 & Active interpersonal skills training & 102 & 111 & 24 & 63 & 2.84 & Agree \\
\hline 33 & Self management skills training & 100 & 192 & 6 & 2 & 3.30 & Agree \\
\hline 34 & Good decision making and communication skills & 42 & 158 & 60 & 40 & 2.67 & Agree \\
\hline 35 & Emotional regulation skills & 31 & 144 & 77 & 48 & 2.53 & Agree \\
\hline 36 & $\begin{array}{l}\text { Higher institutions authorities should set up committee } \\
\text { against indecent dressing. }\end{array}$ & 90 & 72 & 68 & 70 & 2.61 & Agree \\
\hline 37 & $\begin{array}{l}\text { Compulsory inclusion of religious/moral studies in GS } \\
\text { programme of higher institutions. }\end{array}$ & 66 & 116 & 56 & 62 & 2.62 & Agree \\
\hline 38 & Proper and adequate sex education & 74 & 76 & 80 & 70 & 2.51 & Agree \\
\hline 39 & Enlightenment campaign against indiscriminate sex & 88 & 72 & 72 & 68 & 2.60 & Agree \\
\hline 40 & Counselling and rehabilitation services & 75 & 96 & 74 & 55 & 2.64 & Agree \\
\hline
\end{tabular}

Table 4 shows the students' agreement with a mean score of 2.50 and above that measures like family interventions, active interpersonal skills, self-management skills, good decision making and communication skills, emotional regulation skills and setting up committee against indecent dressing by the university authorities could be effective measures for curbing risky sexual and health behaviours in higher institutions in Enugu state. 


\section{Discussion}

The findings of the study revealed the prevalence of risky sexual and health behaviours among students in tertiary institutions in Enugu state. This agrees with the findings of Getachew et al (2016) that the most vulnerable group of premarital sexual behaviour were the youths and adolescents who often involve themselves in risky sexual and health behaviour such as early sexual initiation, indiscriminate sex life, irregular use of condom and having sex with high-risk individuals such as HIV and AIDs victims. Again, the findings of the study align with Keto et al (2020) that the rate of risky sexual behaviours continue to be on the increase among the adolescent population which is a reflection of the processes of adolescents development.

The findings of the study showed that a number of factors have been enumerated as motivation for indulgence in risky sexual and health behaviours. Supporting this finding is the research work of Srahbzu et al (2020) that adolescents who have experienced abuse by others and had antisocial behaviours associated with alcohol and drug have been found to have increased chance of engaging in risky sexual behaviours. They also attributed the following as possible factors promoting engagement in risky sexual and health behaviours: socio-economic status, sexually active peers, instability in the home, single parenthood and sibling sexual activity. Olaleye et al. (2020) also attributed factors like age, level of education, sexual knowledge and sources of sex information, peer influence, religious beliefs and economic problems to be among those influencing adolescents' sexual decision making.

The findings of the study revealed that risky sexual and health behaviour has a lot of impact on the adolescents' psycho-social development. This agrees with the findings of Shrestha (2019) who although noted that indulgence in premarital sex is not a big issue but at the same time acknowledged the impact on psycho-social development of adolescents to include among others regrets, loss of self-respect, depression, loss of family support and suicidal death. Also, Keto (2020) and Getchew et al. (2016) also observed that engagement in sexual risky behaviours leads to various reproductive health challenges thus affecting adolescents' psychological well-being.

Furthermore, the findings of the study revealed family interventions (good parental training and adequate monitoring), active interpersonal skills training, selfmanagement skills training, emotional regulation skills, inclusion of religious and moral studies in GS courses of higher institutions, putting up a serious fight against indecent dressing by university authorities, setting up counseling and rehabilitation service to be among the psycho-social measures that could be effective in curbing risky sexual and health behaviours. This agrees with the findings of Olaleye (2020) who maintained that there is still inadequate information regarding culturally acceptable sexual behaviour to the adolescents and thus suggests appropriate information enlightenment. Doubova et al (2017) suggest that behaviour-based sex education and intervention programs be designed to help adolescents acquire knowledge about disease transmission and prevention. 


\section{Conclusion}

Sex on an individual level is a want and a need on species level. This is simply to save the society from going into extinction. But in as much as sex is vital for procreation, premarital sex remains a taboo socially, culturally and religiously. Adolescents often are ignorant of the harm associated with risky sexual behaviours as well as adequate knowledge of how and where to seek help for their health challenges. Need for intervention in risky sexual activities of adolescents becomes vital to save these future leaders of tomorrow from the consequences of risky sexual and heath behaviours on their reproductive health and psychological well-being.

\section{Recommendations}

The researchers recommend as follows:

1) Parents should lay good behavioural standard for their children and also monitor the association their child keeps. Adequate and proper child rearing/parenting should be the watchword. Parents are admonished to always remember the Biblical injunction "Spare the child and spoil the rod" and also "Train up the child in the way he should go, and when he is old, he will not depart from it".

2) Nonchalant attitude of parents is highly condemned. There should be regular and uninformed visit to their wards in higher institutions. This will help to checkmate some social vices among them.

3) University authorities should provide proper counseling on good communication skills, emotion regulation skills and self-management skills.

4) Entrepreneurial studies such as tailoring, bakery, hair dressing and saloon, auto mechanics among others should be included as compulsory GS courses in higher institutions. This is to provide a forum where adolescents will use their energy and time to engage in useful and profitable ventures rather in risky sexual behaviours.

5) University authorities should put up a serious fight against indecent dressing pattern among female students who almost go naked in their appearance which is implicated as one of the contributing factors to risky sexual behaviours. This could be achieved by setting up a "committee against indecent dressing" in each department with the head of department as the chairman, 3 lecturers and the students' course representatives as members. Here, the various course representatives are expected to submit names of indecent dressed students to lecturers who finally reports to the head of department for appropriate sanctions.

\section{Conflict of Interest Statement}

The authors declare no conflicts of interests. 


\begin{abstract}
About the Authors
Dr. Nkechi Uzochukwu Okeke is a Lecturer in the Department of Educational Foundations, Nnamdi Azikiwe University, Awka, Nigeria. She is a scholar in Educational Psychology. A prolific writer with area of interest in Psychology of Learning and Adolescence Psychology. Dr. Nkechi has published with many local and international journals.
\end{abstract}

Elizabeth Ifeoma Anierobi is a Lecturer in Nnamdi Azikiwe University, Awka, Nigeria. She is an educational psychologist and a prolific writer with interest in learning, adolescents' behaviour and special needs education. She has authored and co-authored many articles in both national and international journals.

Oparaugo Ursula Ifeoma is a Lecturer in the Department of Educational Foundations, Faculty of Education at Nnamdi Azikiwe University, Awka, Nigeria. She holds a Master degree in Educational Psychology and currently a PhD scholar in the above department.

\title{
References
}

Abdissa, B., Addisie, M. \& Seifu, W. (2017). Premarital sexual practices, consequences and associated factors among regular undergraduate female students in AmboUniversity, Oromia regional state, central Ethiopia. Health Science Journal. Retrieved from https://www.researchgate.net/publication/319386963 Premarital Sexual Practice s Consequences and Associated Factors among Regular Undergraduate Fem ale Students in Ambo University Oromia Regional State Central Ethiopia201 $\underline{5}$

Allen, M. D. \& Waterman, H. (2019). Stages of adolescence. American academy of Padiatrics. Retrieved from https://www.healthychildren.org

Doubova, S. V., Martinez-Vega, I. P., Infante-Castaneda, C. \& Perez-Cuevas, R. (2017). Effects of an internet-based education intervention to prevent high-risk sexual behaviour in Mexican adolescents. Health Education Research, 32(6), 487-498.

Keto, T., Tilahun, A. \& Mamo, A. (2020). Risky knowledge, attitude and practice towards risky sexual behaviours among secondary and preparatory students of Metu town, South Western Ethiopia. BMC PublicH. Retrieved from https://bmcpublichealth.biomedcentral.com

Maslow, A. (1970). Motivation and personality (2nd edition). Harper \& Row: New York.

Nishtha, C. \& Siddharth, S. (2019). Defining "High-risk sexual behaviour" in the context of substance use. Journal of Psychosexual Health. Retrieved from http://journals.sagepub.com

Okeke, N. U. \& Joe-Akunne, C. O. (2020). Psychological dimensions of violence and influence on emotional adjustment of adolescents in tertiary institution in Anambra state. Journal of the Nigerian Academy of Education, 16(1), 238-250 
Olaleye, A. O., Obiyan, M. O. \& Folayan, M. O. (2020). Factors associated with sexual and reproductive health behaviour of street-involved young people: Findings from a baseline survey in Southwest Nigeria. Reproductive Health, 17 (94). Retrieved from https://reproductive-healthjournal.biomedcentral.com

Olusegun, B. E. (2019). Investigation of factors that induce premarital sexual intercourse among adolescents in secondary schools in Nigeria. European Scientific Journal. Retrieved from URL: http://dx.doi.org/10.19044/esj.2019.v/5n7p129

Shrestha, R. B. (2019). Premarital sexual behaviour and its impact on health among adolescents. Journal of health promotion. Retrieved from https://www.nepjol.info/index.php/jhp/article/view/25496

Srahbzu, M. \& Tirfeneh, E. (2020). Risky sexual behaviour and associated factors among adolescents aged 15-19 years at government high schools in Aksum town, Tigray, Ethiopia: An institution-based, cross-sectional study. Available online at https://doi.org/10.1155/2020/3719845.

UNESCO (2011). Tertiary education (ISCED levels 5 to 8). Retrieved from https://en.unesco.org/

WHO (2002). Definitions of sexual health- Minnesota department of health. Retrieved from https://www.health.state.mn.us

WHO (2012). Introduction to adolescence and to adolescent health: Training course in sexual and reproductive health research, Geneva 2012. Retrieved from https://www.gfmer.ch. 

will be applied to their work. Under the terms of this license, no permission is required from the author(s) or publisher for members of the community to copy, distribute, transmit or adapt the article content, providing a proper, prominent and unambiguous attribution to the authors in a manner that makes clear that the materials are being reused under permission of a Creative Commons License. Views, opinions and conclusions expressed in this research article are views, opinions and conclusions of the author(s). Open Access Publishing Group and European Journal of Education Studies shall not be responsible or answerable for any loss, damage or liability caused in relation to/arising out of conflicts of interest, copyright violations and inappropriate or inaccurate use of any kind content related or integrated into the research work. All the published works are meeting the Open Access Publishing requirements and can be freely accessed, shared, modified, distributed and used in educational, commercial and non-commercial purposes under a Creative Commons Attribution 4.0 International License (CC BY 4.0). 